\title{
Simulation-Based Learning in Healthcare Ethics Education
}

\author{
Gul Pinar, Sibel Peksoy \\ Department of Nursing, Faculty of Health Sciences, Yıldırım Beyazıt University, Bilkent, Ankara, Turkey \\ Email: gpinar_1@hotmail.com
}

Received 27 November 2015; accepted 25 January 2016; published 28 January 2016

Copyright @ 2016 by authors and Scientific Research Publishing Inc.

This work is licensed under the Creative Commons Attribution International License (CC BY).

http://creativecommons.org/licenses/by/4.0/

(c) (i) Open Access

\begin{abstract}
Every year, millions of people die or get seriously injured due to errors in health practices. Therefore, it is crucial that safe care is enabled and medical errors are minimized in nursing practices and rapid response is given to changing health conditions. In order to train nurses who have professional values and are efficient in their field, simulation-based ethical education has become popular today. Enabling patient safety and preserving legal rights are ethical obligations in terms of personal, institutional and vocational benefit. Simulation is an educational model consisting of ethical and legal concepts. In this context, it is envisaged that simulation-based training such as self-rule, patient consent, patient defensiveness, empathy, communication skills and care in special patient groups are integrated in all health fields. It is considered that this approach regarded as an innovative practice can contribute to the training of health team, which has ethical values. The purpose of this study is to evaluate the current state of the simulation-based ethical training under the light of literature review.
\end{abstract}

\section{Keywords}

Ethical and Legal Content, Nursing Education, Simulation, High-Fidelity Human Simulator

\section{Introduction}

Every year, tens of millions of patients worldwide suffer disabling injuries or death because of unsafe medical practices and care. According to World Health Organization (WHO), almost one in every ten patients is harmed due to preventable causes in the hospital settings (WHO, 2013). It is indicated in 1999 report of the Institute of Medicine (IOM) that every year approximately 44,000 to 98,000 persons die due to errors originating from health practices. In this report, it is emphasized that the number of preventable deaths due to health practices is more than the number of deaths caused by motorized vehicle accidents, breast cancer and AIDS (Kohn \& Cor- 
rigan, 1999). These findings reveal that medical errors are a threat element in enabling patient safety.

In the current list of the Economic Cycle Research Institute (ECRI) (2015) on patient safety, significant problems are cited such as informatics systems, violence management, surgical practices, medicinal practices, patient care, discharge, patient admission and transport (ECRI, 2015). Most of these problems occur because of errors based on communication process. The Joint Commission (TJC) emphasizes that $70 \%$ of sentinel events take place based on insufficient communication (Rosenstein \& O'Daniel, 2008). Therefore, in order to enable patient safety, some national and international institutions care about the professional competence of health professionals. The National League for Nursing (NLN) defines main competencies, as nursing skills need to be "patient centered care and the validation of practice competence crucial for patient safety and quality of care" (NLN, 2010). The IOM indicates in its report that providing high quality and safe care in professional practices need advanced level of skillful and efficient professionals to respond to changing health conditions swiftly. The IOM suggests that simulation is used in the training of health professionals to improve professional competency (Kohn \& Corrigan, 1999). In this context, the Association of Simulation in Health (ASH) was founded in 2004 in the United States to improve patient safety by using simulation techniques (Galloway, 2009). Furthermore, ethical matters started to be considered in the ethical laboratories in Belgium in 2008 as integrated to the simulation training for the first time (Vanlaere et al., 2012).

Simulation provides a level of competence prior to actual patient care from low tech to high tech, which is one method to train health professionals (Hallenbeck, 2012; Göriş et al., 2014). This method can be delivered in various classrooms, clinical and virtual setting based on the goals of the simulation. That training is not simply technical. Because it has become standard practice to train clinical skills using high tech computer, scenario, mannequins, low and high fidelity patient simulators, virtual reality, haptic devices, live actor or standardized patients (Göriş et al., 2014). Simulation activities need to ensure patient safety without danger of harming the patient during the learning process (Galloway, 2009). Clinical practice is essential to nursing, and in its shadow is the theory and research that are needed to advance the science of nursing and improve its clinical application. Faculty needed a dynamic learning activity to help students to recognize the importance of legal and ethical aspects of nursing care.

The practices of simulation also provide to confront ethical challenges with patient safety in healthcare. Hence, the health care authorities allow students to perform all medical procedures and practices on clients with simulated practices in various clinical situations instead of actual patient. The ethical approach believes that variances in culture and society influence whether an act is moral (ANA, 2015a). Simulation training assists determine ethical problems that relate to principles of autonomy, beneficence, justice, informed consent, nonmaleficence, fairness, truthfulness, advocacy, and dedication (Haddad, 2010; Vanlaere et al., 2010; Hallenbeck, 2012; Smith et al., 2012; Vanlaere et al., 2012; Smith et al., 2013). Therefore, the ethics of simulation should be discussed within the context of the larger healthcare systems. Despite the growing popularity of clinical simulation to improve quality and safety in healthcare education, the question of whether students actually transfer the ethical values that takes place in a simulation setting is unknown.

\section{Aim}

In the present study, the evaluation of the current state of simulation-based ethical training was aimed under the light of literature review. This study focused on some of the general issues in ethics and legal of simulation. Ethical considerations contribute to the understanding of effective learning methods and provide guidance to faculty using simulation technology such as cultural barriers, medico legal concerns, and logistics.

\section{The Ethics of Simulation}

Professionalism and professional values is one of basic elements for quality nursing education (American Nurses Association (ANA), 2015b). The content consists of values, ethics, legal concepts, professionalism, and culture, and holds graduates to the values of altruism, autonomy, human dignity, integrity, and social justice (Shahriari et al., 2013; ANA, 2015b). It is expected that nursing graduates will uphold legal and ethical professional standards in their own practice and prevent illegal and unethical care.

Simulation based on three ethical imperatives; keep patients safe, prevent errors and facilitate engaged learning. The simulation environment needs to be one that promotes trust and safety. Simulation leads to better-educated students who developed a more humanistic care towards patients. Simulation scenario is critical in 
the preparation of clinicians prior to that first actual patient experience including collaboration through team training, inter professional, critical thinking, and independent decision-making skills (Bridges et al., 2011; Aebersold \& Tschannen, 2013). The vital component in these scenarios is the prebriefing and debriefing. Especially, effective feedback and debriefing after the simulation can be provide the opportunity to learn in the safety climate and as well as ethical knowledge gaps (Smith et al., 2012). Faculty became concerned that students were failing to realize the value of legal and ethical concepts as applicable to clinical practice.

Anglo-American healthcare ethics are marked by attention to questions of patient autonomy and choice. In fact, a recent study shows that the frequency of moral distress among nurses, arising from unresolved ethical issues, negatively correlates with the quality of nursing care (DeKeyser Ganz \& Berkovitz, 2012). Hence, these conditions culminated in a growing support for the role, management, and integration of ethics quality in healthcare. A Code of Ethics is one way to embed ethics quality in nursing (ANA, 2015b). The Nurses' Code of Ethics consists of normative elements, guiding the conduct and ethical decision making of nurses.

\subsection{Ethical Principles and Theories}

Ethical principles and ethical theories that are used in health practices frequently will be discussed in this section. Basic of ethic principles consist of autonomy, beneficence, nonmaleficence, fidelity, and justice (see Figure 1).

\subsubsection{Ethical Principles}

Autonomy: This principle is an agreement to respect another's right to self-determine a course of action and support of independent decision making (ANA, 2015a). Informed consent is evaluated in the context of autonomy principle. Nurses should provide the required information in health care practices and they shall receive informed consents (Burkhardt \& Nathaniel, 2013). Receiving approval of the individuals in every practice is an ethical obligation. Nurses have responsibility to protect patients' freedom of choice. Patient should get all the information (accurate and true) about difficulties of treatment, during her treatment process, succes of treatment process and quality of life after recovery. Every clinical desicion should:

- Not only have reliable and up-to-date medical information but should have ethical information,

- It must be allowed to the patients that they can make their own desicions,

- Desicions must be patients' own,

- The patients must not be concerned themselves about make a desicion,

- And also they must not feel themselves under pressure.

Beneficence: The basis for this principle is based on the patient advocacy using compassion, taking positive action to help others, and desire to do good in nursing ethics (ANA, 2015a). Beneficence refers to moral obligation to act the benefit the others. The desicion that made by up-to-date and reliable information should gain medical benefit. The aims of the beneficence principle make up the justifications of nursery practices. Nurses should evaluate the possible harms and well-being of served individuals in the case of non-ethical act and insufficient care. In a practice that develops unethically, they should act properly for patient advocacy (Burkhardt \& Nathaniel, 2013).

Nonmaleficence: This principle that describes avoidance of harm or hurt within medical oath and nursing ethics (ANA, 2015a). It is related to beneficence principle. In this principle, injury risk is evaluated during male-

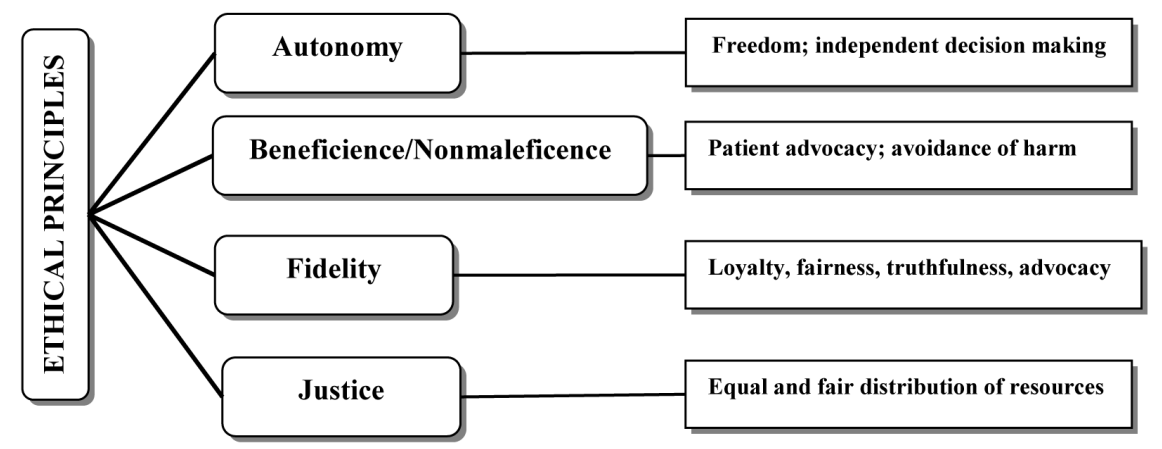

Figure 1. Ethical Principles. Resource: American Nurses Association (2015a). Code of ethics for nurses with interpretive statements. URL (last checked 15 November 2015).

http://www.nursingworld.org/MainMenuCategories/EthicsStandards/Resources/Ethics-Definitions.pdf. 
ficence, harm risk and benefiting. For instance; unnecessary medical interventions made only for gaining experience are included in this scope (Burkhardt \& Nathaniel, 2013).

Fidelity: This principle refers keep a promises, based upon the virtue of caring. Fidelity requires loyalty, fairness, truthfulness, advocacy, and dedication to patients (ANA, 2015a). Fidelity is considered as a universal merit. Honesty and not to lie is among the ethical liabilities. Nevertheless, there are some practices that could violate this principle. Administering placebo medication and withholding information about illnesses that go badly can be given as examples in this scope (Burkhardt \& Nathaniel, 2013).

Justice: This principle means an equal and fair distribution of resources, which is relied on analysis of benefits and burdens of decision. This principle also refers that all citizens have an equal right to the goods distributed, irrespective of what they have contributed or who they are (ANA, 2015a). It is an ethical principle used in the development of health policies and reaching decisions at the institutional level. It aids nurses how the limited resource is used most properly in patient necessities. For instance; for whom the intensive care beds will be assigned and what type of patients will be admitted to the emergency service is considered in this scope (Burkhardt \& Nathaniel, 2013). Justice is guide when medical resources are limited especially sharing treatment resources between patients such as cancer treatments (inadequate and expesive).

\subsubsection{Ethical Theories}

Deontology and utilitarian theory is benefited for reaching ethical decisions in health care practices.

Utilitarianism: This theory that supports what is best for most people. The value of the act is determined by its usefulness, therefore this theory is focused on the outcome or consequences. This theory appears to give advantege to the majority population. Utilitarianism makes research what creates the most happiness for the most people. Most of countries in the health policies are based upon this principle, all over the world (ANA, 2015a).

Deontology: This theory judges the morality of an action based on the action's adherence to rules. Whether an action is right or wrong does not depends on its outcomes. Deontology is based on the work of Immanuel Kant. According to this theory, all individual actions should be done, as if they could become universal law (ANA, 2015a).

The primary liability in terms of ethical angle according to the ANA; is indicated as to preserve health, enable patient safety and protect legal rights (ANA, 2015c). Ethical practices provide benefit in terms of both vocational and institutional points. Therefore, they consist of provisions binding health workers and bring along some ethical obligations. Ethics make up one of the basic elements of professional training in terms of vocational angle. Professional ethics enable raising of professionals who have professionalism and vocational values. Nurses are trained as professionals who provide humanistic care in this context.

In the simulation setting, the educator can manipulate the environment and control the scenario so that learners can practice responses to significant events. In the case of simulated ethic problems, such control is essential to maximize benefits for the learner. Students must balance their ethical responsibilities with those of satisfying stakeholders and reflect complex situations with incomplete information. Students also commented on what they learned by completing the simulation during debrefing.

\section{The Challenges of Simulation for Ethical Issues}

Simulation model is being used today in a variety of health care programs designed to enhance the clinical skills without danger of harming the patient (Galloway, 2009). Research on the use of simulation in nursing education indicates faculty and students like the strategy (Nehring \& Lashley, 2009), but statistical evaluation of the efficacy of simulation is difficult, particularly in relation to its association with individual performance in the actual clinical setting. Whether simulation is used as a teaching strategy or a method of evaluation, the use of simulation to enhance clinical teaching in nursing education may increase personal confidence in clinical performance (Galloway, 2009), but the influence of simulation on competence in clinical judgment and ethical values in practice is unknown. The simulation method provides a way for instructors to demonstrate the top of Miller's pyramid performing the skills in the realistic environment (Munshi et al., 2015).

The educators should respect the dignity of all participants. There are questions specific to management, education, research, the use of technology, registration, medical records, and even the types of simulations (Aggarwal et al., 2010). Simulation-based education has caused various challenges to teachers, students, managers, and patients. In addition to these challenges, ethic education also is a fundamental challenge at the simulation-based 
learning. Ethic education is consisted of the protection of the ethical well-being, the preservation of values and cultural heritage of societies is a major concern of educational system (Aslani et al., 2013). Clinicians receive little training in dealing with death, dying and end of life issues in simulation-based education. The biggest concern about allowing the mannequin to die is the psychological safety of the students. There is discussion within the simulation team about allowing death of the simulated patient to be part of scenario.

\section{Evidence-Based Studies for the Ethics of Simulation}

The problems that occur during patient care by nurses (Vanlaere et al., 2010; Vanlaere et al., 2012), communication-based conflicts (Haddad, 2010; Torrance et al., 2012) and value conflicts (Smith et al., 2012) started to stand out gradually. In this scope, ethical perspective took its place in simulation-based education especially during the past 10 years. Although the studies carried out in this field are limited, usage of technological developments in ethical training is in search of solution about the ethical curriculum arrangement, consideration of humans as a whole with their values, how care that is given to vulnerable/fragile groups gains more importance, how the communication reacts in hard processes and how the scenarios specially fictionalized for this process are to be developed (Haddad, 2010; Vanlaere et al., 2010; Hallenbeck, 2012; Smith et al., 2012; Vanlaere et al., 2012; Smith et al., 2013). Health professional and educators focus on the insufficiencies in reporting of health practices, problems about communication process, lack of team work, and insufficiency of critical thinking skill (JCAHO, 2005). Therefore, ethical matters have been structured as focused on patient care and safety process. In simulation-based ethical education, current matters such as empathy, fragile patient groups, informed consent, communication skills and giving bad news are included (see Figure 2) (Haddad, 2010; Vanlaere et al., 2010; Smith et al., 2012; Vanlaere et al., 2012; Torrance et al., 2012; Chen, 2011).

Dilemmas and conflicts occurring during simulation-based ethical training are experienced by students/health professionals. Preparation is key to a successful simulation program. At the start of the simulation, it is important to set expectations with the students. The simulation team debriefs about their performance and what changes should be focused for the future experiences. Especially, inter professional simulations, team work and communication are essential components of ethical issues. The Inter professional Education Collaborative Expert Panel-IECEP (2011) devoted one of the four domains to values/ethics for inter professional practice. In the study of Smith et al. (2012), crises were generated within the simulation scenario content and breakage points were formed in the conflict process. The students were asked to state their decisions and to analyze their decisions primarily in the solutions following scenario application. Moreover, specific questions for the scenario purpose, the effect of different cultures on the disease and what should be considered in the future are discussed. During the debriefing process, systematic reasons are provided to student thoughts, acts and responses, and simulation training is completed. In both of the studies conducted by Vanlaere et al. (2010, 2012), the simulation is used for the development of empathy skills. In these studies, elderly care makes up the case samples of the scenario. It was aimed that empathy skill development and raising awareness of health professionals and students was achieved. It was emphasized that the care given to the patients should consist of empathy skill and therefore ethical learning process should be started for the care givers to gain specific experience. It was indicated that ethical learning is not only a theoretical concept but at the same time it enables care givers to question themselves (Vanlaere et al., 2010; Vanlaere et al., 2012). In the study of Haddad et al. (2010), patient consent and communication process was focused. It was emphasized in this study that nursing students can transform their

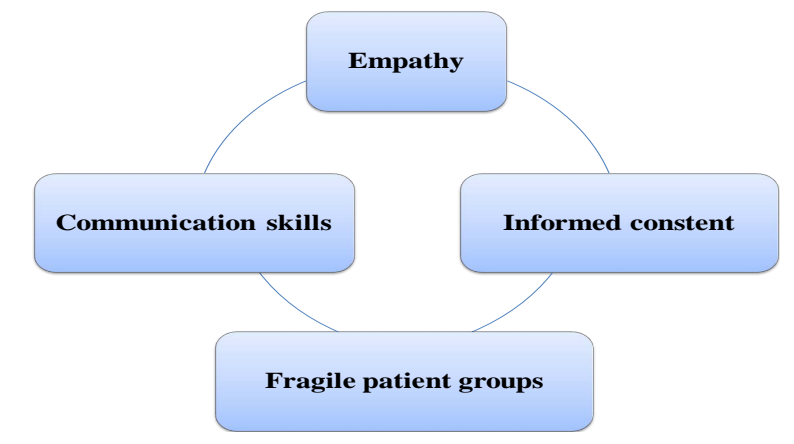

Figure 2. Simulation-based current matters in ethical education. 
experiences to clinical practice. In Chen's (2011) study, the conflicts experienced in the learning process were evaluated by ethical imaging with the theme "how bad news is given in vital crises. In this study, it was emphasized that communication skills were focused on information obtaining generally and therefore very few persons had sufficient bad news giving experience and/or they were insufficient in general. Simulation-based education enables the discussion of effective and ineffective communication methods in this process as well. Furthermore, it was emphasized that simulation usage is an obligation today for patient safety and is an opportunity in prevention of communication-based errors of students before they enter into clinical practice.

Fundamental education and teaching techniques used in scripting and fictionalization of ethical matters in simulation-based education are transformational learning and socratic learning (Smith et al., 2012; Smith et al., 2013; Robinson et al., 2014). Another learning method used in simulation and expressed as reflection makes up a portion of transformational learning (Akpinar, 2010). The purpose in these educational methods is to learn, feel and draw a conclusion that could be used comfortably at the end of the education the events/situations in the vocational practice by living as the contributions of simulation-based education for students and individuals (Smith et al., 2012; Mert et al., 2011). What is expected from the students at the end of education is to transfer their experiences in this education process to real life and to find a solution more easily for problems encountered in the vocational process. Transformational learning experience is effective in nursing practices for learning the significance of legal and ethical matters (Smith et al., 2013). Students live a personal experience by this method and have the opportunity to share their experiences in the solutions achieved at the end of the education. In addition to the evaluation of the scenario in this process, it is a factor supporting learning of feedbacks of the teachers (Akpinar, 2010). It is seen that socratic method and reflection method are used in studies which aim empathy skill development (Vanlaere et al., 2010; Vanlaere et al., 2012). In the study of Vanlaere et al. (2012), it is emphasized that "optimal level care provision" opinion in care ethics is the result of a product requiring reflection. In the study, it is indicated that this learning technique is used for imaging/fancying development of care providers at the same time.

Simulation in healthcare is delivered in many different ways, from low fidelity tech to high fidelity simulation (HFS) tech computer-controlled mannequins include standardized patients (SPs), virtual reality, haptic devices and hybrid simulation (Haddad, 2010; Hallenbeck, 2012; Smith et al., 2012; Smith et al., 2013). HFS has a high degree of realism but we need to be asked this is always necessary? High tech program require the resources to maintain the use of the mannequins. It is indicated that HFS usage in simulation contributes not only to the skill development of the students but also supports achieving communication, leadership and team collaboration. Students develop practice skills before entering the clinical practice field without forming any risk for patients. It contributes patient safety as well (Hallenbeck, 2012). HFS takes its place as an innovative education approach in simulation and enables the discussion of legal and ethical problems along with the developed scenarios when it is integrated with the transformational education technique. Thus, ethical standards and professional values could be developed in nursing practices (Smith et al., 2012). SPs can be used to give feedback and assessment of novice learners. SPs are individuals who are trained to describe a patient with specific problem in a realistic setting. Consent is always an issue in simulation training. In Haddad's (2010) study, communication problems experienced in patient consent obtaining in the scenario fictionalized by standard patients were included. According to scenario, the SPs may react with denial, tears, anger, yelling when they receive bad news or depressed. SPs is to protect actual patients from risks and they take on the suffering another but they need to get back in character.

In the scenarios developed in simulation education, general practices faced in the clinic are focused (Gör et al., 2014). However, it is observed that the applications made in terms of ethical competency are limited. However, there must be a learning process experienced after ethical education that is given theoretically. All scenarios fictionalized in simulation education bring along ethical approaches. As a scenario is developed; defined legal and ethical maters should be related with advanced level suggestions, a technique appropriate to the study method must be selected, attendants and leaders must be determined, cases must progress as planned and cultural differences must be respected (Smith et al., 2012). Scenario development and continuing education with appropriate scenarios and well managing the breakage points are an important part of education (Smith et al., 2012). In addition to all of these developments experienced in simulation-based education, one of the points to be considered in this education perspective is enabling a multidisciplinary collaboration. Milton (2013) considered possible ethical problems in professions and emphasized that multidisciplinary collaboration in simulation education is mandatory. 


\section{Conclusion}

Simulation in healthcare provides a unique tool to increase identify ethics issues that related to the learner's skills and patient safety. Simulation-based learning is consistent with ethical theories, building on prior knowledge and ensuring ethical knowledge transfer. Technical and nontechnical skills have been identified as necessary to provide safe, competent patient care. Healthcare providers are challenged to use simulation-training method to provide the students' ethical values. Including simulation-based learning model, where ethical values are contained in health field, it has great importance. Simulation team needs to share what has worked, what has not worked at meetings and publishing. Educators should use evidence-based strategies to enhance the students' clinical judgment.

\section{References}

Aebersold, M., \& Tschannen, D. (2013). Simulation in Nursing Practice: The İmpact on Patient Care. The Online Journal of Issues in Nursing, 18, Manuscript 6.

Aggarwal, R., Mytton, O. T., Derbrew, M., Hananel, D., Heydenburg, M., Issenberg, B., MacAulay, C., Mancini, M. E., Morimoto, T., Soper, N., Ziv, A., \& Reznick, R. (2010). Training and Simulation for Patient Safety. Qualty Safe Health Care, 19, i34-i43. http://dx.doi.org/10.1136/qshc.2009.038562

Akpınar, B. (2010). Transformative Learning Theory: Learning by Transforming and Changing. Anadolu University Journal of Social Sciences, 10,185-198.

American Nurses Association (ANA) (2015a). Short Definitions of Ethical Principles and Theories Familiar Words, What Do They Mean? http://www.nursingworld.org/MainMenuCategories/EthicsStandards/Resources/Ethics-Definitions.pdf

American Nurses Association (ANA) (2015b). Professional Standards.

http://www.nursingworld.org/MainMenuCategories/ThePracticeofProfessionalNursing/NursingStandards

American Nurses Association (ANA) (2015c). American Nurses Association Position Statement on Risk and Responsibility Providing Nursing Care.

http://www.nursingworld.org/DocumentVault/Position-Statements/Ethics-and-Human-Rights/RiskandResponsibility.pdf

Aslani, G., Senobari, M., Rostaminejad, M. M., \& Jafari, E. M. (2013). Identification and Management of Ethical Challange in E-Learning Systems. Social and Behavioral Sciences, 83, 214-218.

Bridges, D. R., Davidson, R. A., Odegard, P. S., Maki, L. V., \& Tomkowiak, J. (2011). Interprofessional Collaboration: Three Best Practice Models of İnterprofessional Education. Medical Education Online, 16, 6035-6035.

Burkhardt, M. A. \& Nathaniel, A. K. (2013). Ethical Priciples. In Ş. E. Alpar, N. Bahçecik, \&Ü.Karabacak (Eds.), Ethics Issues in Contemporary Nursing (pp. 52-78). 3th Press. İstanbul: İstanbul Tip Kitapevi.

Chen, R. P. (2011). Moral İmagination in Simulation-Based Communication Skills Training. Nursing Ethics,18, $102-111$. http://dx.doi.org/10.1177/0969733010386163

DeKeyser Ganz, F., \& Berkovitz, K. (2012). Surgical Nurses’ Perceptions of Ethical Dilemmas, Moral Distress and Quality Care. Journal of Advanced Nursing, 68, 1516-1525. http://dx.doi.org/10.1111/j.1365-2648.2011.05897.x

Economic Cycle Research Institute (ECRI) (2015). Top 10 Patient Safety Concerns for Healthcare Organizations. http://www.ecri.org/PatientSafetyTop10

Galloway, S. J. (2009). Simulation Techniques to Bridge the Gap Between Novice and Competent Healthcare Professionals. The Online Journal of Issues in Nursing, 14, Manuscript 3.

Göriş, S., Bilgi, N., \& Bayındır, S. K. (2014). Use of Simulation in Nursing Education. Düzce University Journal of Health Science Institute, 4, 25-29.

Haddad, A. (2010). What Health Science Students Learn from Playing a Standardized Patient in a Ethics Course. Cambridge Quarterly of Healthcare Ethics, 19, 481-487. http://dx.doi.org/10.1017/S096318011000037X

Hallenbeck, V. J. (2012). Use of High-Fidelity Simulation for Staff Education/Development. Journal for Nurses in Staff Development, 28, 260-269. http://dx.doi.org/10.1097/NND.0b013e31827259c7

Kohn, L. T., \& Corrigan, J. M. (1999). To Err İs Human: Building a Safer Health System. Institute of Medicine (IOM), Washington DC: National Academy Press.

Mert, H., Bilik, Ö., Yıldırım, Sarı, H., \& Üstün, B. (2011). A Learning Experience: Reflection. Dokuz Eylül University Nursing High School Electronic Journal, 4, 89-93.

Milton, C. L. (2013). Ethical Issues Surrouding Interprofessional Collaboration. Nursing Science Quarterly, 26, 316-318. http://dx.doi.org/10.1177/0894318413500314

Munshi, F., Lababidi, H., \& Alyousef, S. (2015). Low- versus High-Fidelity Simulations in Teaching and Assessing Clinical 
Skills. Journal of Taibah University Medical Sciences, 10, 12-15. http://dx.doi.org/10.1016/j.jtumed.2015.01.008

National League for Nursing (2010). Outcomes and Competencies for Graduates of Practical/Vocational, Diploma, Associate Degree, Baccalaureate, Master's, Practice Doctorate, and Research Doctorate Programs in Nursing. New York: National League for Nursing.

Nehring, W., \& Lashley, R. (2009). Nursing Simulation: A Review of the Past 40 Years. Gaming, 40, 528-552. http://dx.doi.org/10.1177/1046878109332282

Robinson, E. M., Lee, S. M., Zollfrank, A., Jurchak, M., Frost, D., \& Grace, P. (2014). Enhanching Moral Agency: Clinical Ethics Residency for Nurses. Hastings Center Report, 44, 12-20. http://dx.doi.org/10.1002/hast.353

Rosenstein, A. H., \& O’Daniel, M. (2008). A Survey of the Impact of Disruptive Behaviors and Communication Defects on Patient Safety. Joint Commission Journal on Quality and Patient Safety, 34, 464-471.

Shahriari, M., Mohammadi, E., Abbaszahed, A., \& Bahrami, M. (2013). Nursing Ethical Values and Definitions: A Literature Review. Iranian Journal of Nursing and Midwifery Research, 18, 1-8. http://www.ncbi.nlm.nih.gov/pmc/articles/PMC3748548/?report=printable

Smith, K. V., Klaassen, J., Zimmerman, C., \& Cheng, A. (2013). Patient Simulation Learning Experience to Teach Legal and Ethical Issues. Journal of Professional Nursing, 29, 168-173. http://dx.doi.org/10.1016/j.profnurs.2012.04.020

Smith, K. V., Witt, J., Klaassen, J., Zimmerman, C., \& Cheng, A. (2012). High-Fidelity Simulation and Legal/Ethical Concepts: A Transformational Learning Experience. Nursing Ethics, 19, 390-398. http://dx.doi.org/10.1177/0969733011423559

Torrance, C., Mansell, I., \& Wilson, C. (2012). Learning Objects? Nurse Educators' Views on Using Patients for Student Learning: Ethics and Consent. Education for Health, 25, 92-97.

Vanlaere, L., Coucke, T., \& Gastmans, C. (2010). Experimental Learning of Empathy in a Care-Ethics Lab. Nursing Ethics, 17, 325-336. http://dx.doi.org/10.1177/0969733010361440

Vanlaere, L., Timmermann, M., Stevens, M., \& Gastmans, C. (2012). An Explarative Study of Experiences of Healthcare Providers Posing as Simulated Care Receivers in a “Care-Ethical” Lab. Nursing Ethics, 19, 68-79. http://dx.doi.org/10.1177/0969733011412103

World Health Organization (2013). Ethical İssues in Patient Safety Research: Interpreting Existing Guidance. http://apps.who.int/iris/bitstream/10665/85371/1/9789241505475_eng.pdf 